\title{
High-precision elemental and stable isotope mapping of a Mesoarchean stromatolite: implications for primitive phototrophic metabolism and paleoecology
}

\author{
LUKAS NICOL ${ }^{1}$, PIERRE SANS-JOFRE ${ }^{2}$, PHILIP W. \\ FRALICK $^{3}$, MUNIRA AFROZ ${ }^{4}$, LAURELINE PATRY ${ }^{5}$, \\ MARTIN HOMANN $^{6}$, TRISTAN GOBERT ${ }^{7}$ AND STEFAN V. \\ LALONDE $^{8}$ \\ ${ }^{1}$ CNRS - UMR 6538 Laboratoire Géosciences Océan \\ ${ }^{2}$ IMPMC, CNRS, Sorbonne Université, MNHN \\ ${ }^{3}$ Lakehead University \\ ${ }^{4}$ CNRS-UMR6538 Laboratoire Géoscience Océan \\ ${ }^{5}$ CNRS-UMR6538 Laboratoire Géosciences Océan \\ ${ }^{6}$ University College London \\ ${ }^{7}$ CNRS-UMR6539 LEMAR \\ ${ }^{8}$ CNRS-UMR6538 Laboratoire Géosciences Océan \\ Presenting Author: lukas.nicol@etu.uca.fr
}

The 2.94 Ga Ball Assemblage of the Red Lake Greenstone Belt (Ontario, Canada) hosts the oldest thick carbonate platform found on Earth and the oldest undisputed stromatolites in the Northern Hemisphere. Among the diverse sedimentary lithologies associated with this platform, the stromatolitic carbonates present a unique opportunity to evaluate the metabolisms of primitive phototrophic bacteria by the coupled isotopic analyses of their inorganic carbon sources (reflected by the carbonate) and the biomass resulting from their metabolism (reflected by organic matter). We performed detailed elemental (micro-XRF mapping and HR-ICP-MS) and isotopic analyses $\left(\delta^{13} \mathrm{C}_{\mathrm{Carb}}, \delta^{18} \mathrm{O}_{\mathrm{Carb}}\right.$ and $\left.\delta^{13} \mathrm{C}_{\mathrm{org}}\right)$ on a single stromatolite from the shoreline north of Galena Island to produce the first highprecision solution-mode trace element and IRMS-based isotopic mapping of a single Archean stromatolite (136 powdered samples covering approximately $20 * 30 \mathrm{~cm}$ ), which we interpret alongside similar data from exploration drill cores spanning the platform as well as compiled data from other Archean carbonate platforms. While the carbonate isotopic compositions are relatively stable, organic matter shows a remarkable range in $\delta^{13} \mathrm{C}_{\text {org }}$, spanning -25 to $-10 \%$ (PDB). These values are not easily explained by methanogenesis, metamorphism, or variations in carbon source. Such values could represent the activity of anoxygenic photosynthesizers fixing carbon via the 3hydroxypropionate bicycle (3HP), similar to modern-day Chloroflexi, however, the operation of this type of carbon fixation pathway during the Archean is controversial. This work reveals the underappreciated potential of high-precision, spatially-resolved stable isotope analysis of ancient stromatolites for understanding metabolic pathways and paleoecology in Earth's early phototrophic communities. 